\title{
Association between brain natriuretic peptide and distant metastases in advanced non-small cell lung cancer patients
}

\author{
KATSUHIRO MASAGO ${ }^{1}$, SHIRO FUJITA ${ }^{2}$, YOSUKE TOGASHI ${ }^{1}$, KAORU IRISA ${ }^{1}$, \\ YUICHI SAKAMORI ${ }^{1}$, YUKIMASA HATACHI ${ }^{1}$, AKIKO FUKUHARA ${ }^{1}$, HIROKI NAGAI $^{1}$, \\ YOUNG HAK KIM $^{1}$, TADASHI MIO ${ }^{1}$ and MICHIAKI MISHIMA ${ }^{1}$ \\ ${ }^{1}$ Department of Respiratory Medicine, Graduate School of Medicine, Kyoto University, Kyoto; \\ ${ }^{2}$ Division of Integrated Oncology, Institute of Biomedical Research and Innovation, Kobe, Japan
}

Received October 22, 2010; Accepted December 28, 2010

DOI: $10.3892 / \mathrm{ol} .2011 .247$

\begin{abstract}
This study aimed to investigate the relationship between clinicopathological factors and plasma brain natriuretic peptide (BNP) levels in non-small cell lung cancer (NSCLC) patients. A total of 133 patients with advanced NSCLC were included in this study. The level of BNP was determined at the time of diagnosis. The BNP plasma concentration was measured using a chemiluminescent enzyme immunoassay kit. The univariate relationship between each independent clinicopathological variable and plasma BNP was examined using the Chi-square test. The survival curves were determined using the Kaplan-Meier method. According to the cut-off value of plasma BNP levels (11.5 and $22.4 \mathrm{pg} / \mathrm{ml}$ ), plasma BNP negatively correlated with the presence of metastases (Chi-square test, $\mathrm{p}=0.0374$ and $\mathrm{p}=0.0098$, respectively). However, no significant association between patient survival time and plasma BNP levels was found. Reduced plasma BNP levels in advanced NSCLC patients with metastases were noted and the possibility was raised that BNP decreases distant metastases of advanced NSCLC patients.
\end{abstract}

\section{Introduction}

Lung cancer is a leading cause of cancer-related mortality worldwide and is expected to remain a major public health problem for the foreseeable future. Numerous phase III studies have been conducted aiming at validating therapeutic impact on patient survival among patients with advanced non-small cell lung cancer (NSCLC) (?).

The heart is a sophisticated endocrine gland that synthesizes a family of peptide hormones using three genes. These cardiac

Correspondence to: Dr Katsuhiro Masago, Department of Respiratory Medicine, Graduate School of Medicine, Kyoto University, 54 Syogoin-Kawaracho, Sakyo-ku, Kyoto 606-8507, Japan

E-mail: masago@kuhp.kyoto-u.ac.jp

Key words: brain natriuretic peptide, non-small cell lung cancer, metastases, prognostic factor hormones are stored as three prohormones: atrial natriuretic peptide (ANP), brain natriuretic peptide (BNP) and C-type natriuretic peptide (1-4). The ANP prohormones comprise four peptide hormones: ANP, vessel dilator, kaliuretic peptide and long-acting natriuretic peptide. These peptides decrease up to $97 \%$ of human pancreatic, breast, colon, prostate, kidney and ovarian carcinomas as well as small-cell and squamous cell lung cancer cells within $24 \mathrm{~h}$ in cell culture (5). In vivo the four cardiac hormones eliminate up to $80 \%$ of human pancreatic adenocarcinomas, $66 \%$ of human breast cancers and up to $86 \%$ of human small-cell lung cancers in athymic mice. The anticancer mechanisms of these hormones target the Ras-MEK 1/2-ERK 1/2 kinase cascade in cancer cells. The four cardiac hormones also inhibit up to $95 \%$ of the basal activity of Ras, $98 \%$ of the phosphorylation of MEK $1 / 2$ and $97 \%$ of the basal activity of ERK $1 / 2$. They also block the activity of mitogens, such as the ability of epidermal growth factor to stimulate ERK (5).

ANP and BNP plasma concentrations were elevated in patients with congestive heart failure $(6,7)$. The level of BNP was shown to be sufficiently accurate for diagnosing, monitoring and predicting prognosis in those patients (8). Of the six hormones, BNP had no antitumor effect against various tumor cell lines, including pancreatic, breast and small cell lung cancer $(9,10)$. However, to the best of our knowledge, no reports exist on the prognostic effect of these peptide hormones or the relationship between clinicopathological factors and plasma levels in advanced NSCLC patients who are anticipated to have a high cardiac burden.

In this study, the concentration of plasma BNP levels in NSCLC patients was measured and the relationship between these levels and clinicopathological factors was investigated.

\section{Patients and methods}

Patients and methods. A total of 133 patients admitted to Kyoto University Hospital with advanced NSCLC between September 2007 and May 2009 were included in this study. Plasma samples were collected from all 133 patients.

The level of BNP was determined at the time of diagnosis. Venous blood $(4 \mathrm{ml})$ was obtained from each patient and transferred to tubes containing aprotinin and ethylene- 
diamine-tetra-acetic acid, and stored at $-20^{\circ} \mathrm{C}$ until the measurements were taken. Plasma concentration of BNP was measured using a chemiluminescent enzyme immunoassay kit (MI02 Shionogi BNP; Shionogi Co. Ltd., Osaka, Japan) and an immunoassay system (MI02; A\&T Co. Ltd., Yokohama, Japan). The minimum quantity of a human BNP detectable using this system is $4 \mathrm{pg} / \mathrm{ml}$.

Statistical analysis. The univariate relationship between each independent clinicopathological variable and plasma BNP was examined using the Chi-square test. The survival curves were determined using the Kaplan-Meier method. The log-rank test was used to evaluate the differences between the survival curves. The data were analysed using JMP 6 software (SAS Institute, Cary, NC, USA).

\section{Results}

Patient characteristics. Table I shows the characteristics of the 133 advanced NSCLC patients who were admitted to our institution between June 2007 and May 2009. The patients were Japanese, and included 95 (71.4\%) males and 38 (28.6\%) females, with a median age of 61 years (range 34-88). The pathological diagnoses are listed in Table I and the number of dominant adenocarcinomas was 85 (63.9\%). A total of $44(33.1 \%)$ patients were non-smokers and $89(66.9 \%)$ patients were former or current smokers. The Eastern Cooperative Oncology Group performance status was 0-1 for 104 patients and 2-3 for 29 patients. Of the 133 patients, 62 (46.6\%) had been treated with platinum doublets, $30(22.6 \%)$ with cytotoxic agent monotherapy, 7 (5.3\%) with epidermal growth factor receptor tyrosine kinase inhibitors as the first-line regimen, $5(3.8 \%)$ with chemo-radiotherapy, 3 (2.2\%) with thoracic radiotherapy and $26(19.5 \%)$ with best supportive care.

Plasma brain natriuretic peptide. The mean and median concentration of plasma BNP was 11.5 and $22.4 \mathrm{pg} / \mathrm{ml}$, respectively. A statistical comparison of the plasma BNP in our study population showed significantly lower levels in patients with metastasis compared to those without metastasis (two-tailed $\mathrm{t}=1.969, \mathrm{df}=9.177, \mathrm{p}=0.05$, Fig. 1). According to the cut-off level of plasma BNP (11.5 and $22.4 \mathrm{pg} / \mathrm{ml})$, plasma BNP negativity correlates with the presence of metastases (Table II-A and B) (Chi-square test, $\mathrm{p}=0.0374$ and $\mathrm{p}=0.0098$, respectively).

Plasma brain natriuretic peptide and survivals. Positive or negative plasma BNP was determined by the cut-off values of 11.5 and $22.4 \mathrm{pg} / \mathrm{ml}$, which are the 25 and $50 \%$ percentiles, respectively. No significant association between patient survival time and plasma BNP level was noted (Figs. 2 and 3).

\section{Discussion}

In this study, reduced plasma BNP levels were noted in advanced NSCLC patients with metastases. We also found that plasma BNP levels did not affect the survival of patients with or without chemotherapy.

The most recently-discovered property of the cardiac natriuretic peptides is their ability to inhibit the growth of cancers
Table I. Patient characteristics and treatment $(n=133)$.

\begin{tabular}{|c|c|}
\hline Characteristics & $\mathrm{n}(\%)$ \\
\hline \multicolumn{2}{|l|}{ Age (years) } \\
\hline Range & $34-88$ \\
\hline Median & 61 \\
\hline \multicolumn{2}{|l|}{ Gender } \\
\hline Female & $38(28.6)$ \\
\hline Male & $95(71.4)$ \\
\hline \multicolumn{2}{|l|}{ Smoking status } \\
\hline Non-smoker & $44(33.1)$ \\
\hline Smoker & $89(66.9)$ \\
\hline Former & $46(34.6)$ \\
\hline Current & $43(32.3)$ \\
\hline \multicolumn{2}{|l|}{ Performance status } \\
\hline $0-1$ & $104(78.2)$ \\
\hline$>2$ & $29(21.8)$ \\
\hline \multicolumn{2}{|l|}{ Tumor histology } \\
\hline Adenocarcinoma & $85(63.9)$ \\
\hline Squamous cell carcinoma & $24(18.0)$ \\
\hline NSCLC & $22(16.5)$ \\
\hline Large & $2(0.6)$ \\
\hline \multicolumn{2}{|l|}{ Pathological stage } \\
\hline IIIB & $55(41.4)$ \\
\hline IV & $78(58.6)$ \\
\hline \multicolumn{2}{|l|}{ Therapy } \\
\hline Platinum doublet & $62(46.6)$ \\
\hline Cytotoxic agent monotherapy & $30(22.6)$ \\
\hline EGFR TKIs & $7 \quad(5.3)$ \\
\hline Chemo-radiotherapy & $5(3.8)$ \\
\hline Radiation & $3(2.2)$ \\
\hline Best supportive care & $26(19.5)$ \\
\hline
\end{tabular}

NSCLC, non-small cell lung cancer; EGFR TKIs, epidermal growth factor receptor tyrosine kinase inhibitors.

in vitro and in vivo (9-13). In any cancer cell line that has been examined in vitro $(9-11,13)$ and in vivo $(12)$, including that of human pancreatic adenocarcinoma cells, human breast adenocarcinoma, human squamous cell lung cancer and human small lung cancer cells, vessel dilator has had the strongest anticancer effects, whereas BNP had no effect on the cancer cells. However, in our study, the plasma BNP level was significantly lower in patients with metastasis, indicating that BNP decreases distant metastases in patients with NSCLC.

We hypothesized that plasma BNP inhibits the profibrotic action of tumor growth factor- $\beta$ (TGF- $\beta$ ) (14), thereby decreasing distant metastases. TGF- $\beta$ promotes an epithelial to mesenchymal transition that is associated with increased tumor cell motility, invasion and metastasis $(15,16)$.

Moreover, BNP promotes vessel growth by increasing the number of endothelial progenitors and enhancing their functional properties (17). The provasculogenic properties of 
Table II. Correlation between metastases and serum BNP according to the cut-off BNP levels.

\section{A, $11.5 \mathrm{pg} / \mathrm{ml}$}

\begin{tabular}{lccc}
\hline & No. of cases & \multicolumn{2}{c}{ Metastases } \\
\cline { 3 - 4 } & & Positive & Negative \\
\hline Negative $(<11.5 \mathrm{pg} / \mathrm{ml})$ & 34 & 25 & 9 \\
Positive $(>11.5 \mathrm{pg} / \mathrm{ml})$ & 99 & 53 & 46 \\
Total & 133 & 78 & 55 \\
\hline
\end{tabular}

Chi-square test, $\mathrm{p}=0.0374$.

$\mathrm{B}, 22.4 \mathrm{pg} / \mathrm{ml}$

\begin{tabular}{lccc}
\hline & No. of cases & \multicolumn{2}{c}{ Metastases } \\
\cline { 3 - 4 } & & Positive & Negative \\
\hline Negative $(<22.4 \mathrm{pg} / \mathrm{ml})$ & 66 & 46 & 20 \\
Positive $(>22.4 \mathrm{pg} / \mathrm{ml})$ & 67 & 32 & 35 \\
Total & 133 & 78 & 55 \\
\hline
\end{tabular}

Chi-square test, $\mathrm{p}=0.0098$; BNP, brain natriuretic peptide.

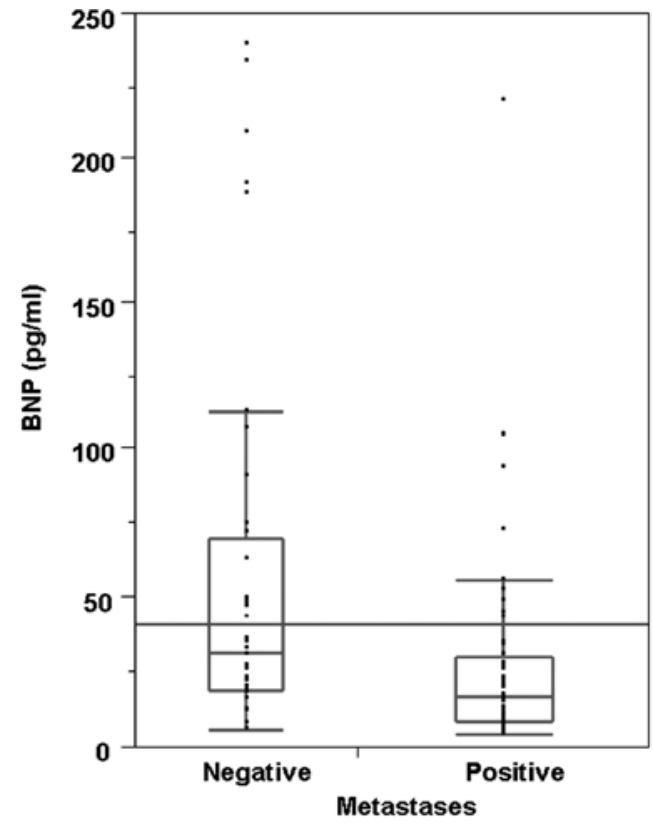

Figure 1. Serum levels of brain natriuretic peptide in relation to the presence of metastases in the patients (two-tailed $\mathrm{t}=1.969, \mathrm{df}=9.177, \mathrm{p}=0.05$ ).

BNP may account for certain beneficial effects in NSCLC patients in terms of normal vasculogenesis in the tumor bed which differs from plasma vascular endothelial growth factor (VEGF). Subsequently, the association between plasma BNP and VEGF in vivo should be investigated.

No prognostic significance of plasma BNP was found whether or not chemotherapy was administered. The level

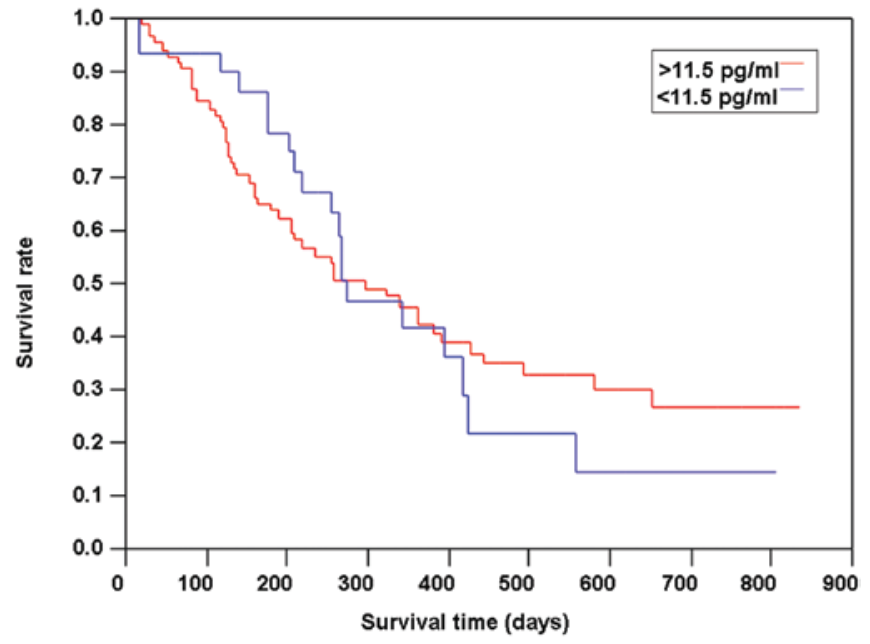

Figure 2. Kaplan-Meier analysis of the survival of 133 patients according to the serum brain natriuretic peptide levels. The differences between the groups were evaluated using the log-rank test $(\mathrm{p}=0.9196)$.

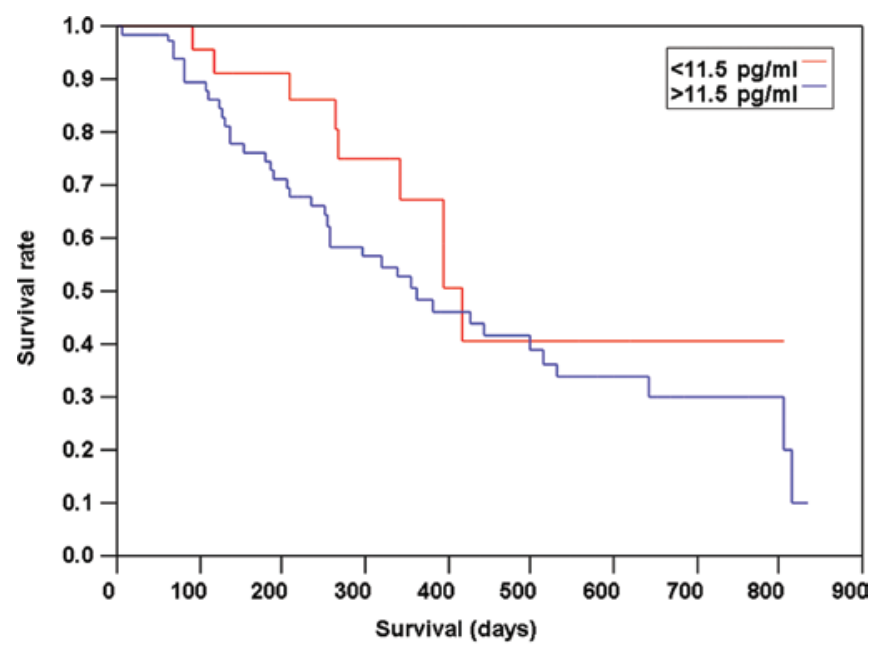

Figure 3. Kaplan-Meier analysis of the survival of 113 patients who received chemotherapy according to the serum brain natriuretic peptide levels. The differences between the groups were evaluated using the log-rank test $(\mathrm{p}=0.9919)$.

of BNP has been shown to be sufficiently accurate to predict prognosis in those patients (7). To the best of our knowledge, no reports exist regarding the relationship between prognosis and the levels of cardiac peptide hormones, including BNP, although advanced NSCLC patients anticipate to have a high cardiac burden. The reason is that in many cohorts dealing with advanced NSCLC patients, clinical stage is not always considered to be a prognostic factor.

The limitations of our study include the small sample size, the heterogeneity of the treatment regimens and its retrospective nature. However, we showed reduced plasma BNP levels in advanced NSCLC patients with metastases, suggesting that BNP decreases the distant metastases of advanced NSCLC patients. In conclusion, whether BNP is a potential therapeutic option for inhibiting distant metastases of advanced NSCLC patients remains to be determined. 


\section{References}

1. Gardner DG, Chen S, Glenn DJ and Grigsby CL: Molecular biology of the natriuretic peptide system: implications for physiology and hypertension. Hypertension 49: 419-426, 2007.

2. Gardner DG, Kovacic-Milivojevic BK and Garmai M: Atrial natriuretic peptides. In: Molecular Biology of the Natriuretic Peptides. Vesely DL (ed). Research Signpost, Trivandrum, pp15-38, 1977.

3. Vesely DL: Atrial natriuretic peptide prohormone gene expression: hormones and diseases that upregulate its expression. IUBMB Life 53: 153-159, 2002.

4. Vesely DL: Natriuretic hormones. In: The Kidney: Physiology and Pathophysiology. 4th edition. Alpern RJ (ed). Elsevier/ Academic Press, San Diego, CA, 2006.

5. Vesely DL: Metabolic targets of cardiac hormones' therapeutic anti-cancer effects. Curr Pharm Des 16: 1159-1166, 2010.

6. Burnett JC Jr, Kao PC, Hu DC, et al: Atrial natriuretic peptide elevation in congestive heart failure in the human. Science 231: 1145-1147, 1986.

7. Yoshimura M, Yasue H, Okumura K, et al: Different secretion patterns of atrial natriuretic peptide and brain natriuretic peptide in patients with congestive heart failure. Circulation 87: 464-469, 1993.

8. Cowie MR, Struthers AD, Wood DA, et al: Value of natriuretic peptides in assessment of patients with possible new heart failure in primary care. Lancet 350: 1349-1353, 1997.

9. Vesely BA, Song S, Sanchez-Ramos J, et al: Five cardiac hormones decrease the number of human small-cell lung cancer cells. Eur J Clin Invest 35: 388-398, 2005.
10. Vesely BA, Song S, Sanchez-Ramos J, et al: Four peptide hormones decrease the number of human breast adenocarcinoma cells. Eur J Clin Invest 35: 60-69, 2005.

11. Vesely BA, McAfee Q, Gower WR Jr and Vesely DL: Four peptides decrease the number of human pancreatic adenocarcinoma cells. Eur J Clin Invest 33: 998-1005, 2003.

12. Vesely DL, Clark LC, Garces AH, McAfee QW, Soto J and Gower WR Jr: Novel therapeutic approach for cancer using four cardiovascular hormones. Eur J Clin Invest 34: 674-682, 2004.

13. Vesely BA, Fitz SR, Gower WR Jr and Vesely DL: Vessel dilator: most potent of the atrial natriuretic peptides in decreasing the number and DNA synthesis of human squamous lung cancer cells. Cancer Lett 233: 226-231, 2006.

14. Kapoun AM, Liang F, O'Young G, et al: B-type natriuretic peptide exerts broad functional opposition to transforming growth factor-beta in primary human cardiac fibroblasts: fibrosis, myofibroblast conversion, proliferation, and inflammation. Circ Res 94: 453-461, 2004.

15. Bierie $B$ and Moses HL: Transforming growth factor beta (TGF-beta) and inflammation in cancer. Cytokine Growth Factor Rev 21: 49-59, 2010.

16. Tian M and Schiemann WP: The TGF-beta paradox in human cancer: an update. Future Oncol 5: 259-271, 2009.

17. Shmilovich H, Ben-Shoshan J, Tal R, et al: B-type natriuretic peptide enhances vasculogenesis by promoting number and functional properties of early endothelial progenitor cells. Tissue Eng Part A 15: 2741-2749, 2009. 